\title{
Emotional expression during attention-deficit/hyperactivity disorders treatment: initial assessment of treatment effects.
}

\author{
Christopher J. Kratochvil \\ University of Nebraska Medical Center, ckratoch@unmc.edu \\ D. Faries \\ Eli Lilly
}

Brigette S. Vaughan

University of Nebraska Medical Center, bvaughan@unmc.edu
A. Perwien
Eli Lilly
J. Busner
PharmaStar

See next page for additional authors

Tell us how you used this information in this short survey.

Follow this and additional works at: https://digitalcommons.unmc.edu/com_psych_articles

Part of the Psychiatry Commons

\section{Recommended Citation}

Kratochvil, Christopher J.; Faries, D.; Vaughan, Brigette S.; Perwien, A.; Busner, J.; Saylor, K.; Kaplan, S.; Buermeyer, C.; and Swindle, R., "Emotional expression during attention-deficit/hyperactivity disorders treatment: initial assessment of treatment effects." (2007). Journal Articles: Psychiatry. 17. https://digitalcommons.unmc.edu/com_psych_articles/17

This Article is brought to you for free and open access by the Psychiatry at DigitalCommons@UNMC. It has been accepted for inclusion in Journal Articles: Psychiatry by an authorized administrator of DigitalCommons@UNMC. For more information, please contact digitalcommons@unmc.edu. 


\section{Authors}

Christopher J. Kratochvil, D. Faries, Brigette S. Vaughan, A. Perwien, J. Busner, K. Saylor, S. Kaplan, C. Buermeyer, and R. Swindle 


\title{
Emotional Expression During Attention-Deficit/ Hyperactivity Disorders Treatment: Initial Assessment of Treatment Effects
}

\author{
C.J. Kratochvil, M.D. ${ }^{1}$ D. Faries, Ph.D., ${ }^{2}$ B. Vaughan, A.P.R.N., ${ }^{1}$ A. Perwien, Ph.D. ${ }^{2}$ \\ J. Busner, Ph.D., ${ }^{3}$ K. Saylor, Ph.D., ${ }^{4}$ S. Kaplan, M.D., ${ }^{3}$ C. Buermeyer, Ph.D., ${ }^{4}$ and \\ R. Swindle, Ph.D. ${ }^{2}$
}

\begin{abstract}
Objective: The purpose of this research was to provide an initial examination of the effects of atomoxetine and stimulants on emotional expression using a newly developed scale for assessing emotional expression in children with attention-deficit/hyperactivity disorder (ADHD).

Method: The parent-rated Expression and Emotion Scale for Children (EESC) was collected during two studies. During a cross-sectional validation study, the EESC was completed to assess the child's current treatment and retrospectively for previous medication. In a randomized, placebo-controlled trial of atomoxetine, the EESC was collected at baseline and endpoint.

Results: In the validation study, no statistically significant differences in EESC scores were found between groups taking atomoxetine $(n=74)$ and stimulants $(n=105)$. Patients who switched from a stimulant to atomoxetine $(n=40)$ had greater improvement in emotional expression than those switched to another stimulant $(n=21)(p=0.008)$. In the clinical trial, no difference in rates of worsening of emotional expression were observed (atomoxetine $8.8 \%$, placebo $12.3 \% ; p=0.440$ ).

Conclusion: No treatment differences in emotional expression were observed based on current medications. However, stimulant patients needing to switch medications may have greater improvements in emotional expression by switching to atomoxetine.
\end{abstract}

\section{INTRODUCTION}

A LTHOUGH RESEARCH HAS DOCUMENTED the efficacy of treatments on the core symptoms of attention-deficit/hyperactivity disorder (ADHD) and the common physical side effects of medications used to treat it (AACAP 2002), quantitative evaluations of changes in emotional expression as potential treatment-emergent effects have been rare. This may be attributed to a general lack of data on the tolerability of pediatric pharmacotherapies, or to the lack of validated instruments for measuring emotional expression. One notable experimental study demonstrating negative emotional side effects of stimulant medication is Whalen et al.'s

\footnotetext{
${ }^{1}$ University of Nebraska Medical Center, Omaha, Nebraska.

${ }^{2}$ Eli Lilly \& Company, Indianapolis, Indiana.

${ }^{3}$ PharmaStar, Wayne, Pennsylvania.

${ }^{4}$ Neuroscience Inc, Herndon, Virginia.
} 
(1989) cross-over demonstration of observable "dysphoria" induced by methylphenidate (MPH). In a pair of blinded placebo-drug crossover designs, they used an observer rating measure in a laboratory group game task. The rating items comprising the dysphoria rating measure were "Withdrawn, hanging back," "Sad or unhappy," and "Flat or unemotional." In both studies, children on MPH during the task were rated significantly more dysphoric than on days when they were on placebo.

Some clinicians who use medication to treat ADHD in children have experienced a parent saying "I don't want to make my child a zombie." Clinicians have also seen personality changes in certain children treated with ADHD pharmacotherapy. Employing the construct of "negative emotional expression," including affective blunting, mood lability, and the "zombie effect," a new parent-reported scale has been developed in an attempt to quantify the impact of medication on emotional expression in children: The Expression and Emotion Scale for Children (EESC).

\section{EESC development}

Development of the EESC followed the guidelines outlined by DeVillis (1991): Definition and refinement of the construct to be measured, generation of an item pool, examination of understandability and appropriateness of the items and response choices, and determination of the psychometric properties of the measure. Qualitative research methods, including focus groups and cognitive interviews, were used to refine the construct and develop an initial item pool. On the basis of information collected from the focus groups, and the input of clinician investigators with expertise in ADHD, an initial 37-item scale was developed. Cognitive interviews were then conducted to examine the understandability and appropriateness of the items and response choices on the scale.

The product of these initial qualitative phases was the EESC Version 1, a 29-item scale designed to assess the impact of pharmacotherapy on emotional expression in children treated for ADHD (Kratochvil et al. 2004). Each item of the EESC is rated on a 5-point scale $(1=$ 'Not true at all', $2=$ 'A little true', 3 $=$ 'Somewhat true', $4=$ 'Pretty much true', $5=$ 'Very much true'). Of the 29 items, 14 addressed positive aspects of emotional expression ("My child seems happy."), with the remaining 15 concentrating on negative qualities ("My child zones out."). The scale items asked parents to rate the child's mood, emotional state, and personality characteristics considering the past 2 weeks. For scoring the EESC, the positive items scores were transformed such that higher scores represent 'worse' symptoms for all items and subscales. Specifically, for positive items, the score analyzed for each item was ' 6 - raw score'. Total and subscale scores were then computed as the sum of the (transformed) item scores. Maximum likelihood factor analysis with varimax orthogonal rotation was used to identify three potential subscales of the EESC: A 13-item positive emotions subscale, a 10-item emotional flatness subscale, and a 5-item emotional lability subscale.

Details of the development process and a full assessment of the basic psychometric properties from the validation study have been documented in a separate report (Perwien et al., submitted). In brief, the validation study confirmed that the EESC total score and its subscales have adequate psychometric properties, although minor modifications to the scale were recommended (see Appendix). Adequate internal consistency was observed (Cronbach's alpha of 0.91 for the total, 0.87 for positive, 0.90 for flat, 0.86 emotional lability subscales). Convergent and divergent validity were established using multiple scales and test-retest reliability was found to range from 0.65 to 0.69 (intraclass correlation coefficients). The recommended modifications were to improve the floor effects of the flat subscale. However, initial testing of the new items (with improvements in floor effects) in a subset of patients demonstrated a high correlation $(r=0.92)$ with the original items. Thus, the analysis here focuses on the full set of patients with the original items.

\section{Objectives}

The objective of the research presented here was to employ the EESC for an initial 
examination of the effects of atomoxetine and stimulants on emotional expression. Data from both the validation study and a randomized clinical trial were used. The validation study includes cross-sectional data from parents of children with ADHD treated with either atomoxetine or a stimulant. This allows for a comparison of treatment groups on the basis of naturalistic selection of treatments. This study also collected retrospective data from past treatments, providing an opportunity for preliminary assessment of reported changes in emotional expression as children change treatments. Data from the randomized, doubleblind clinical trial allowed a prospective assessment of changes in emotional expression over time for patients starting treatment with atomoxetine as compared to placebo.

\section{METHODS}

\section{Validation study}

The EESC validation study was conducted at three experienced ADHD research sites in Pennsylvania, Maryland, and Nebraska, This study included 179 parents/guardians (hereafter referred to as parents) and their 6 to 12year-old children with ADHD who were taking either atomoxetine or stimulant medication. The goals of this study were to examine the psychometric properties of the scale and make any necessary modifications. Parents of children with a diagnosis of ADHD were recruited from the community by print advertisements, letters to community clinicians, and from the investigators' own practices. Parents and children had to possess an appropriate level of cognitive skills so that they could communicate suitably with investigators. Per entry criteria, the child's ADHD must have been diagnosed by an M.D. or Ph.D. trained in the assessment of pediatric mental health disorders, and the child must have been on a single pharmacotherapy treatment for ADHD, either atomoxetine or a stimulant. The children could not be on any other concurrent psychotropic medication. In addition, the current ADHD treatment must have been stable, that is, no recent changes in medication or dose of medication for a minimum of 2 weeks.
Each parent-child dyad attended a single clinic visit at their participating site. After informed consent was obtained from the parent and written assent was obtained from the child, the parent provided demographic and family information, as well as the child's medication history, including rationale for prior medication changes. Parents then completed the EESC scale for their child on the basis of his or her current treatment. If the child had switched medications in the recent past, a retrospective EESC based on the child's most recent previous ADHD medication was also completed. A subset of parents completed a follow-up EESC approximately 2 weeks later to allow for test-retest reliability assessment. The computer-based Diagnostic Interview for Children and Adolescents-IV (DICA-IV; Reich et al. 1997) was completed by the parent to assess co-morbid disorders. A positive diagnosis of ADHD based on the DICA-IV was not required for study participation. Other measures included the Conners' Parent Rating Scale-Revised: short form (CPRS-R:S; Conners 1997), The Child Behavior Checklist (CBCL; Achenbach 1991; Achenbach and Rescorla 2001), and the child-rated Child Depression Inventory (CDI; Knight et al. 1988; Kovacs 1992), and Multidimensional Anxiety Scale for Children; (MASC; March et al. 1997) were also collected at the initial time point.

\section{Clinical trial}

The EESC scale was included as part of a battery of measurements at 9 of 14 sites in a randomized, double-blind, atomoxetine clinical trial. In this trial, 288 (208 from sites where the EESC was collected) 6 to 12-year-old children with a Diagnostic and Statistical Manual of Mental Disorders, $4^{\text {th }}$ edition, text revision (DSM-IV-TR; American Psychiatric Association 2000) diagnosis of ADHD were randomized to either atomoxetine morning dosing, atomoxetine evening dosing, or placebo for approximately 6 weeks of double-blind treatment. The ADHD diagnosis was established at study entry using the Kiddie Schedule for Affective Disorders and Schizophrenia for School Aged Children-Present and Lifetime, Behavioral Disorders Supplement (K-SADS-PL: Beh) 
module criteria for ADHD (Kaufman et al. 1997). The K-SADS-PL:Beh was administered by a trained and approved researcher at each site. Patients were required to score at least 1.5 standard deviations (SD) above the age/gender norm for their ADHD diagnostic subtype on the ADHD Rating Scale-Parent Version, Investigator Scored (DuPaul 1991; Faries et al. 2001). A medication washout of 5 half-lives prior to randomization to treatment was required for children who were taking medication at the time of study entry. Use of other psychotropic medications or psychoactive substances during the course of the study was not permitted. EESC data were collected at baseline (randomization visit) and treatment end point ( 6 weeks or early discontinuation). Collection of the EESC data was a secondary objective of the trial. The primary purpose was to gather data to assess the relative efficacy and safety of morning and evening dosing of atomoxetine.

\section{Statistical methods}

Analysis of variance (ANOVA) was used to test the null hypothesis of no group (treatment) differences in EESC scores in both the validation study and clinical trial data. ANOVA models for the clinical trial data analysis included terms for investigational site, treatment group, and baseline score. ANOVA models from the validation study included investigational site, age, gender, race, treatment group, co-morbid diagnoses, such as oppositional defiant disorder (ODD), conduct disorder (CD), enuresis, encopresis, dysthymia, depression, and baseline score (when change scores were the outcome variable). The inclusion of additional covariates was important in the analyses of the Validation study as group comparisons from this study are based on naturalistically selected and not randomly formed treatment groups. Thus, the covariates serve as a potential adjustment for selection bias. As a sensitivity analysis, disease severity measures (ADHD, depression, anxiety) were also added to the validation study models as covariates. The results of the sensitivity analyses were consistent and are not reported here.

Categorical changes in EESC scores in the randomized clinical trial were also assessed using chi-square tests. Changes were categorized based on whether they were less than or at least 1 standard error of the mean (SEM). Changes of at least 1 SEM have been previously utilized as a measure of meaningful change (Wyrwich et al. 1999).

Two-sided, 0.05 significance levels were used for all statistical tests. All statistical analyses were performed using SAS (1999).

\section{RESULTS}

\section{Baseline patient characteristics}

Tables 1 and 2 summarize the patient characteristics for participants in the validation study and clinical trial, respectively. Patient characteristics are provided by current (ongoing) treatment group in the validation study and by the randomized treatment group in the clinical trial. The clinical trial population was less advanced in grade level, with a slightly higher percentage of males. Differences in rates of co-morbid diagnoses may be due in part to the different diagnostic tools-as the DICA is only used to suggest provisional diagnoses that would then need examination by a physician to either confirm or refute the diagnoses. Overall, the samples appeared to be reasonably representative of the general ADHD population, predominantly male, combined subtype, and often presenting with a co-morbid diagnosis.

In the randomized clinical trial, the atomoxetine and placebo treatment groups had similar patient characteristics. In the validation study where treatment with atomoxetine or a stimulant was determined by choice, some differences were noted. Specifically, patients taking atomoxetine tended to be older, less likely to be Caucasian, more likely to have co-morbid depression, and had slightly less severe ADHD symptoms than patients taking stimulants. In addition, the groups had different treatment histories, with almost two thirds of the atomoxetine patients having tried a stimulant in the past but only $20 \%$ of stimulant patients having tried atomoxetine in the past. This discrepancy was likely due to the relatively recent availability of atomoxetine at the time of the study. 
TAble 1. Summary of Patient Characteristics-Validation StUdy

\begin{tabular}{|c|c|c|c|c|}
\hline & Atomoxetine & Stimulants & Test stat ${ }^{a}$ & $p$ value \\
\hline$n$ & 74 & 105 & & \\
\hline Age, mean (SD) & $9.8(1.8)$ & $9.1(1.8)$ & 2.56 & 0.011 \\
\hline Grade, mean (SD) & $4.6(1.9)$ & $4.0(2.0)$ & 2.11 & 0.037 \\
\hline Male (\%) & 67.6 & 65.7 & 0.07 & 0.780 \\
\hline Race (\% Caucasian) & 67.6 & 81.0 & 4.19 & 0.041 \\
\hline Spec education service use (\%) & 49.3 & 36.1 & 2.89 & 0.089 \\
\hline \multicolumn{5}{|l|}{ Most recent prior treatment $(\%)$} \\
\hline Atomoxetine & 0.0 & 20.0 & & \\
\hline Stimulants & 63.0 & 44.8 & & \\
\hline None & 37.0 & 35.2 & & \\
\hline CPRS ADHD Index, mean (SD) & $63.7(13.3)$ & $67.8(12.3)$ & -2.10 & 0.037 \\
\hline MASC Total, mean (SD) & $50.4(9.4)$ & $52.2(9.4)$ & -1.25 & 0.207 \\
\hline CDI Total, mean (SD) & $49.5(8.4)$ & $47.6(9.4)$ & 1.41 & 0.159 \\
\hline CBCL Total, mean (SD) & $59.4(10.8)$ & $62.3(10.5)$ & -1.84 & 0.068 \\
\hline \multicolumn{5}{|l|}{ Co-morbid diagnoses ${ }^{\mathrm{b}}$} \\
\hline ODD & 44.1 & 38.4 & 0.55 & 0.459 \\
\hline Phobias & 19.1 & 14.1 & 0.74 & 0.391 \\
\hline Enuresis & 17.7 & 9.1 & 2.68 & 0.101 \\
\hline Conduct disorder & 10.3 & 9.1 & 0.07 & 0.795 \\
\hline Major depression & 7.4 & 0.0 & 7.50 & 0.006 \\
\hline
\end{tabular}

$\mathrm{SD}=$ standard deviation; $\mathrm{CPRS}=$ Conners' parent rating scale; $\mathrm{ADHD}=$ attention-deficit/hyperactivity disorder; MASC $=$ multidimensional anxiety scale for children $\mathrm{CDI}=$ child depression inventory; $\mathrm{CBCL}=$ child behavior checklist; ODD = oppositional defiant disorder; DICA-IV = diagnostic interview for children and Adolescents-IV; df $=$ degrees of freedom.

${ }^{a}$ Test statistics were $t$-statistics for continuous measures (with df ranging from 142 for the MASC, 163 for CDI, 175 for $\mathrm{CBCL}$, and 177 for age, grade, and CPRS due to missing data) and chi-square statistics (1 df) for binary variables. ${ }^{\mathrm{b}}$ Diagnosis suggested by DICA-IV.

Table 2. Summary of Patient Characteristics-Clinical Trial

\begin{tabular}{|c|c|c|c|c|}
\hline & Atomoxetine & Placebo & Test stat ${ }^{a}$ & p value \\
\hline$n$ & 140 & 68 & & \\
\hline Age, mean (SD) & $8.8(1.6)$ & $8.9(1.7)$ & -0.13 & 0.900 \\
\hline Grade, mean (SD) & $2.9(1.6)$ & $3.0(1.7)$ & -0.45 & 0.656 \\
\hline Male (\%) & 77.1 & 73.5 & 0.33 & 0.567 \\
\hline Race (\% Caucasian) & 72.9 & 70.6 & 0.12 & 0.732 \\
\hline Prior stimulant treatment (\%) & 28.8 & 41.2 & 3.20 & 0.074 \\
\hline \multicolumn{5}{|l|}{ ADHD subtype } \\
\hline Hyperactive/Impulsive & 2.1 & 4.4 & 0.84 & 0.359 \\
\hline Inattentive & 23.6 & 23.5 & 0.00 & 0.995 \\
\hline Mixed & 74.3 & 72.1 & 0.12 & 0.732 \\
\hline CGI-Severity & $5.1(0.8)$ & $5.0(0.7)$ & 0.20 & 0.809 \\
\hline \multicolumn{5}{|l|}{ Co-morbid Diagnoses ${ }^{\mathrm{b}}$} \\
\hline ODD & 31.4 & 38.2 & 0.95 & 0.330 \\
\hline Conduct disorder & 1.4 & 0 & 0.99 & 0.320 \\
\hline Major depression & 0 & 0 & - & - \\
\hline Phobias & 0 & 0 & - & - \\
\hline
\end{tabular}

$\mathrm{SD}=$ standard deviation; ADHD = attention-deficit/hyperactivity disorder; CGI-severity = Clinical Global Impressions-severity; ODD = oppositional defiant disorder; $\mathrm{df}=$ degrees of freedom; K-SADS = Kiddie Schedule for Affective Disorders and Schizophrenia for School-Aged Children.

aTest statistics were $t$ statistics for continuous measures (with df of 199 for the CGI to 206 for age and grade) and chi-square statistics (1df) for binary variables.

biagnosis confirmed by K-SADS structured diagnostic interview. 
In univariate analyses, EESC scores were not significantly related to most baseline demographics and co-morbid diagnoses. Exceptions in the validation study include higher total scores for patients with phobias, higher emotional lability scores for females and those with $C D$, and higher flat subscale scores for patients with major depressive disorder (MDD). Exceptions in the clinical trial included higher flat subscale scores for minorities and higher total scores for patients with oppositional defiant disorder (ODD).

\section{Assessment of treatment effects}

Results from three analyses of treatment differences in EESC scores are presented in the subsections below: (1) a comparison of EESC scores between groups formed by naturalistically selected treatment (atomoxetine vs stimulants) in the validation study; (2) a comparison of changes in EESC scores from previous to current treatment for patients in the validation study who switched from stimulants to atomoxetine versus patients who switched within the stimulant class of medications; and (3) a comparison of changes in EESC scores from baseline to endpoint (6 weeks) for atomoxetine-versus placebotreated patients in the randomized clinical trial.
Validation study-cross-sectional analysis: Figure 1 summarizes the mean scores for the total score and each of the EESC subscales by the current treatment, atomoxetine or a stimulant. The 'stimulant' group was made up of various treatments, with the most common being Concerta $(43.8 \%)$, Adderall (16.2\%), Ritalin $(16.2 \%)$, and Adderall XR (11.4\%). The differences in scores between patients on atomoxetine [total EESC: mean(SD) 59.3 (17.0)] and on stimulant (total EESC: mean(SD) 60.5 (16.7)) treatment were small and an ANOVA revealed no statistically significant differences $(F[1,138]$ $=0.2, p=0.624]$. There were also no statistically significant differences between treatment groups on the three EESC subscale scores.

Further analysis showed no significant differences between short-(most common: Adderall, Ritalin) and long-acting stimulants (most common: Concerta, Adderall XR) [long acting, $n=60$, mean (SD) $=60.0$ (16.8); short acting, $n=36$, mean (SD) $=61.2$ (16.9); 9 stimulant patients had missing item scores and were excluded from analyses of total scores]. In addition, the differences between $\mathrm{MPH}$ medications and amphetamine medications were not statistically significant [MPH: $n=62$, mean $(\mathrm{SD})=58.9$ (16.9); amphetamine, $n=30$, mean $(\mathrm{SD})=63.6(16.6) ; p=0.165 ; 4$ stimulant

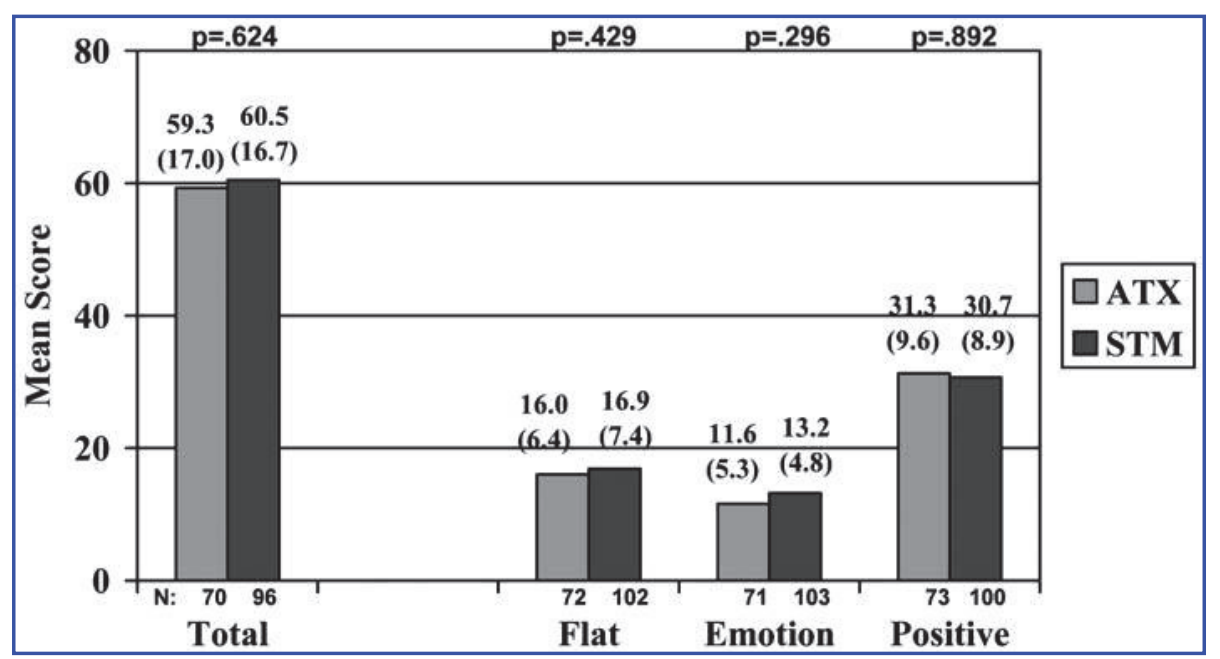

FIG. 1. EESC mean scores based on current treatment, validation study. Values reports are mean (SD). $p$ Values are based on $F$ tests from ANOVA with terms for demographics, site, treatment, and co-morbid diagnoses. $F$ statistics (denominator df) were: Total, 0.2 (138); flat, 0.6 (146); emotion, 1.1 (146); and positive, 0.0 (145). EESC = Expression and emotion scale for children; $\mathrm{SD}=$ standard deviation; $\mathrm{df}=$ degrees of freedom; $\mathrm{ANOVA}=$ analysis of variance. ATX = atomoxetine; STM = stimulant. 
Table 3. Changes from Past to Current Treatment EESC Total Scores-Within Group Changes: Validation Study

\begin{tabular}{lccccr}
\hline Past and Current Treatment & $\mathrm{n}$ & $\begin{array}{c}\text { Prior } \\
\text { mean }(S D)\end{array}$ & $\begin{array}{c}\text { Change: } \\
\text { Prior to current } \\
\text { mean }(S D)\end{array}$ & Test-statistic & $\begin{array}{c}\text { Within-group } \\
\text { p value }\end{array}$ \\
\hline Atomoxetine to Stimulant & 18 & $67.4(17.9)$ & $-6.2(15.1)$ & -1.75 & 0.099 \\
Stimulant to Atomoxetine & 40 & $83.4(24.2)$ & $-21.6(29.1)$ & -4.69 & $<0.001$ \\
Stimulant to Stimulant & 21 & $81.9(21.5)$ & $-15.1(18.5)$ & -3.75 & 0.001 \\
\hline
\end{tabular}

All subscales also demonstrated significant improvement from the prior score. Test statistics/ $p$ values were based on paired t-tests. EESC scales for 8 patients were not fully completed and not included in this analysis.

$\mathrm{SD}=$ standard deviation .

patients were taking modafinil and were excluded from this analysis].

The overall mean item score, across all items and treatments, was 2.14 (note: 2 = 'a little true', 3 = 'somewhat true'). Mean item scores were slightly higher for positively worded items (2.38) as compared to negatively worded items (1.94).

Validation study-retrospective changes: A total of 87 parents completed both a retrospective and current EESC scale. The retrospective scale assessed the child's most recent previously used ADHD medication, and thus was not completed for patients who had not changed medications. Of the 87 parents with both scales completed, 44 were parents of children who had switched from stimulants (24 short acting, 20 long acting) to atomoxetine. Twenty four records were available for children switching within the stimulant class: 11 from short to long acting, 7 switching between long-acting medications, 5 between short-acting medications, and 1 from long-acting to a short-acting stimulant. Nineteen parents provided data about switching from atomoxetine to stimulants.

Table 3 summarizes the changes from past to current EESC within each medication pattern group. Significant differences were noted in mean retrospective EESC total scores, with higher scores for patients with stimulants as their past treatment as opposed to patients with atomoxetine as their past treatment $(F[1,46]=6.7, p=0.013)$. All groups (those switching from stimulants and those switching from atomoxetine) improved upon the switch of medications, with larger improvements from patients switching from stimu- lants. Those on stimulants in the past (whether switching to atomoxetine or another stimulant) also had significant improvements using each of the three EESC subscales.

Figure 2 presents the analysis of changes from retrospective to current EESC scores (total and subscales) for patients switching from stimulants to atomoxetine versus patients switching from a stimulant to a different stimulant. These two groups were compared statistically because they had the largest sample sizes and similar retrospective scores. Patients switching from stimulants to atomoxetine had significantly greater improvements in emotional expression compared to those switching within the stimulant class $(F[1,31]$ $=8.1, p=0.008)$. Whereas those switching to atomoxetine were found to have numerically greater improvements on all three EESC subscales, the difference was driven primarily by improvements in the Emotional Flatness subscale $(F=13.8[1,33], p=0.001)$.

Clinical Trial-changes for atomoxetine- and placebo-treated patients: In the double-blind clinical trial, 136 patients randomized to atomoxetine and 65 patients randomized to placebo had both a baseline and post-baseline EESC scale completed. Table 4 presents the summary statistics on baseline and change scores for the EESC total as well as results of the ANOVA assessment of differences between the atomoxetine and placebo groups. Within-group mean changes over the 6-week trial indicated small but statistically significant improvements for both atomoxetine and placebo-treated patients. The analysis of treatment differences did not detect any statistically significant differences in change scores 


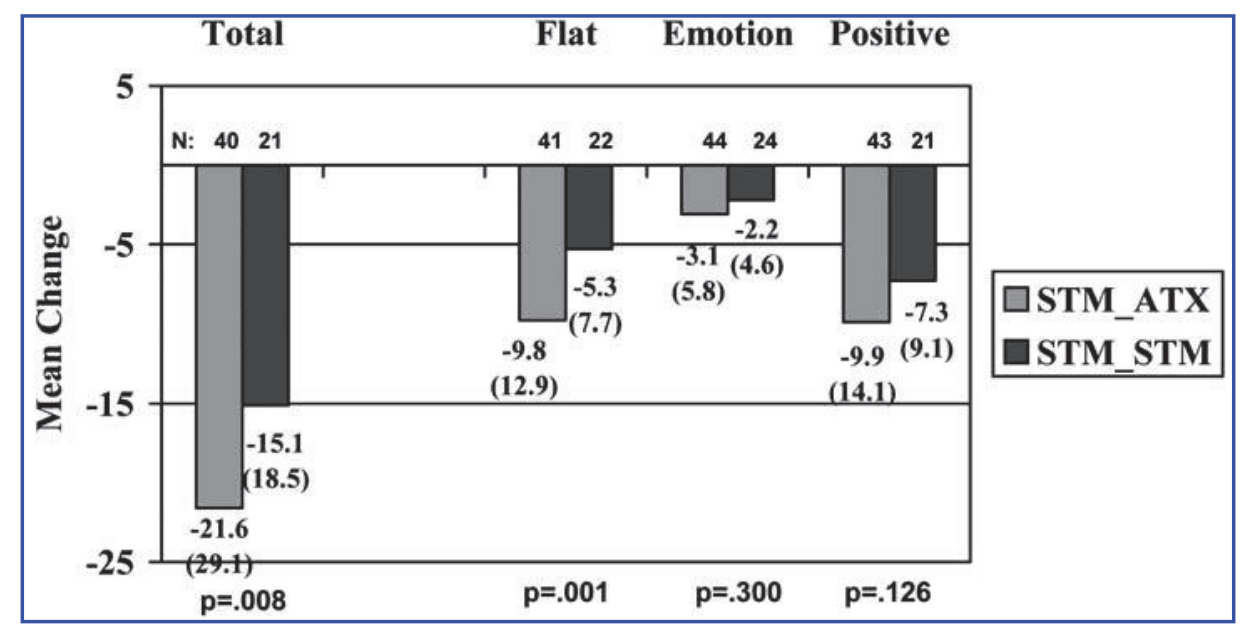

FIG. 2. Changes from retrospective to current EESC scores, validation study. Values reported are mean (SD). STM_ATX-patients switched from a stimulant to atomoxetine; STM_STM = patients switched from a stimulant to another stimulant. $p$ Values are based on F tests from ANOVA with terms for demographics, site, treatment, retrospective score, and co-morbid diagnoses. F statistics (denominator df) were: Total, 8.1 (31); flat, 13.8 (33); emotion, 1.1 (36); and positive, 2.5 (32). EESC = Expression and Emotion scale for children; SD = standard deviation; ANOVA = analysis of variance.

between the atomoxetine and placebo groups for the EESC total $(F[1,190]=0.01, p=0.923)$ and subscale scores.

In addition to evaluating mean changes, patients were also classified on the basis of their changes relative to the SEM. This was done to identify if there were subsets of patients in either treatment group for whom emotional expression changes were potentially problematic and that may be missed in a mean change analysis. The percentages of patients with improvements of more than 1 SEM, no change (improvement or worsening of $<1$ SEM), and worsening of at least 1 SEM were computed for each treatment group. Table 5 summarizes these results. Once again, incidences of

Table 4. Changes from Baseline to End Point in EESC Total Score: Clinical Trial.

\begin{tabular}{|c|c|c|c|c|c|c|}
\hline Treatment & $\mathrm{n}$ & $\begin{array}{c}\text { Baseline } \\
\text { mean (SD) }\end{array}$ & $\begin{array}{l}\text { End point } \\
\text { mean (SD) }\end{array}$ & $\begin{array}{c}\text { Change } \\
\text { Mean (SD) }\end{array}$ & $\begin{array}{l}\text { F statistic } \\
\text { (denom df) }\end{array}$ & $\begin{array}{c}\mathrm{p} \text { value vs } \\
\text { placebo }\end{array}$ \\
\hline \multicolumn{7}{|l|}{ Total score } \\
\hline Atomoxetine & 136 & $63.6(18.3)$ & $60.4(18.5)$ & $-3.1(14.6)$ & $0.01(190)$ & 0.923 \\
\hline Placebo & 65 & $68.2(20.2)$ & $63.6(19.5)$ & $-4.6(15.5)$ & & - \\
\hline \multicolumn{7}{|c|}{ Positive emotions } \\
\hline Atomoxetine & 139 & $31.4(10.3)$ & $31.2(10.0)$ & $-0.2(8.3)$ & $0.00(193)$ & 0.973 \\
\hline Placebo & 65 & $34.0(10.9)$ & $32.9(10.4)$ & $-1.2(7.8)$ & & - \\
\hline \multicolumn{7}{|c|}{ Emotional flatness } \\
\hline Atomoxetine & 137 & $17.7(6.7)$ & $16.5(7.1)$ & $-1.2(6.0)$ & $0.40(192)$ & 0.528 \\
\hline Placebo & 66 & $18.5(9.0)$ & $16.3(7.3)$ & $-2.1(7.3)$ & & - \\
\hline \multicolumn{7}{|c|}{ Emotional lability } \\
\hline Atomoxetine & 138 & $14.6(5.5)$ & $12.7(5.1)$ & $-1.9(4.4)$ & 1.59 (195) & 0.209 \\
\hline Placebo & 68 & $15.7(4.8)$ & $14.1(5.3)$ & $-1.6(3.6)$ & & - \\
\hline
\end{tabular}

EESC $=$ Expression and Emotion scale for children; $\mathrm{SD}=$ Standard deviation; $\mathrm{df}=$ degrees of freedom; $\mathrm{ANOVA}=$ analysis of variance.

$p$ values based on $F$ tests from an ANOVA model on change from baseline to end-point scores with terms for baseline score, site, and treatment. Sample sizes vary across measures due to missing item scores. 
Table 5. Analysis of Categorical Changes in EESC scores by Treatment Group: Clinical Trial

\begin{tabular}{|c|c|c|c|c|c|c|c|c|}
\hline & \multicolumn{3}{|c|}{$\begin{array}{c}\text { Atomoxetine } \\
(\mathrm{n}=136) \\
\text { categorical change }^{a}(\%)\end{array}$} & \multicolumn{3}{|c|}{$\begin{array}{c}\text { Placebo } \\
(\mathrm{n}=65) \\
\text { categorical change }^{a}(\%)\end{array}$} & \multirow{2}{*}{$\begin{array}{c}\text { Chi-square } \\
\text { statistic }\end{array}$} & \multirow[b]{2}{*}{$\mathrm{p}$ value } \\
\hline & Increase & Same & Decrease & Increase & Same & Decrease & & \\
\hline Total score & 8.8 & 62.5 & 28.7 & 12.3 & 63.1 & 24.6 & 0.80 & 0.669 \\
\hline \multicolumn{9}{|l|}{ Subscales } \\
\hline Positive & 13.7 & 67.6 & 18.7 & 12.3 & 64.6 & 23.1 & 0.54 & 0.762 \\
\hline Flat & 8.8 & 64.2 & 27.0 & 10.6 & 68.2 & 21.2 & 0.86 & 0.649 \\
\hline Emotional & 13.8 & 44.9 & 41.3 & 8.8 & 57.4 & 33.8 & 3.01 & 0.222 \\
\hline
\end{tabular}

$\mathrm{EESC}=$ Expression and Emotion scale for children; SEM = standard error of measurement; $\mathrm{df}=$ degrees of freedom.

ancrease represents an increase (worsening) in scores of at least one SEM. Decrease represents improvement of at least 1 SEM. Same represents absolute changes of less than 1 SEM. The SEM was determined by test-retest reliability data for each subscale. Treatment differences in percentages were assessed using chi-square tests with $2 \mathrm{df}$.

worsening between the groups were similar, and there were no statistically significance differences in any of the categories.

\section{DISCUSSION}

The EESC is potentially a useful clinical tool for assessing changes in emotional and personality expression in children treated with pharmacotherapy for ADHD. It goes beyond the traditional focus on monitoring core symptoms of ADHD or commonly reported adverse effects, such as changes in appetite or sleep. Previous work has suggested that the EESC is a reliable and valid tool with three factors: Positive emotional expression, emotional flatness, and emotional lability. This analysis provided the initial use of the EESC to assess medication group differences.

Three main findings regarding treatment effects were suggested by the data. First, for patients on stable treatment with their naturalistically selected medication (suggesting that the medication was at least reasonably tolerated and effective), no treatment differences in emotional expression were observed. This finding included comparisons between atomoxetine and stimulants and between different types of stimulants. Second, the large improvements from the retrospective to current EESC scores for patients changing medications suggest that emotional expression may be improved in those patients experiencing adverse emotional effects by selecting an alternative medication. Patients who switched from stimulant treatments had greater improvements in emotional expression by switching to atomoxetine than to another stimulant. Third, the randomized double-blind placebocontrolled study suggested that atomoxetine treatment did not dramatically improve emotional expression, nor did it negatively affect emotional expression in children.

Limitations to this work include the nonrandomized nature of the treatment comparisons from the validation study and the reliance upon retrospective data to produce EESC scores on past medication treatment. Potential biases from using recall data include the possibility for scores to be influenced by the current state of the parent, knowledge of resolution of problems, and emphasis on salient events over representative events (Gorin and Stone 2001; Henker et al 2002). Given that no prospective differences were found in responsiveness using atomoxetine or placebo, there as yet is no data prospectively demonstrating differential responsiveness to change on the EESC. Thus, it is not absolutely clear whether atomoxetine has no effects on emotional responsiveness, or if EESC will be sensitive in detecting changes in the kind of dysphoria demonstrated by Whalen et al. (1989) with MPH. Additionally, there is no placebocontrolled data yet available using the EESC on stimulant treatment, or blinded comparator studies. These data would be of interest to 
randomized patients needing to switch medications and to assess changes on the new medications. More data on responsiveness of the scale and a greater understanding of the clinical meaning of changes of various magnitudes also will be valuable. Last, minor modifications to the scale have been suggested and additional data using the modified version should be collected.

Because this study represents the first look at medication differences with the EESC, replication and extension to other child clinical and nonclinical samples is needed. However, the information gathered thus far indicates that the EESC has the potential to provide clinically valuable information regarding medication effects on emotional expression in children with ADHD.

\section{DISCLOSURES}

Both the validation study and clinical trial were conducted with funds provided by Eli Lilly \& Company.

Dr. Kratochvil is a consultant to Eli Lilly, Shire, Cephalon, Organon, Pfizer, AstraZeneca, and Boehringer-Ingelheim; speaker for Eli Lilly, and has grant support from Cephalon, McNeil, Shire and Eli Lilly. Dr. Faries is a full time employee and stockholder of Eli Lilly \& Company. Ms. Vaughan has no conflicts to report. Dr. Perwien was an employee of Eli Lilly at the time the study was conducted. She is currently an independent contractor and has been a paid consultant to Eli Lilly. Dr. Busner has received research support from, been on the speaker bureau for, or served as a consultant to BristolMyers Squibb, Eli Lilly, Forest, GlaxoSmith Kline, Merck, Forest, and Shire. She is an employee of United BioSource Corporation. Dr. Saylor receives research/consultancy support from Eli Lilly, Bristol Myers Squibb, Shire, McNeil, New River, and Otsuka. Dr. Kaplan has received research support from, been on the speaker bureau for, or served as a consultant to Bristol-Myers Squibb, Eli Lilly, Forest, GlaxoSmithKline, Ortho-MacNeil, and Shire. Dr. Buermeyer has received research support from and been a consultant to Eli Lilly and Company. Dr. Swindle is an employee and stockholder of Eli Lilly.

\section{REFERENCES}

AACAP: Practice Parameters for the Use of Stimulant Medications in the Treatment of Children, Adolescents, and Adults. JAACAP 41(Supplement):26S-49S, 2002.

Achenbach TM: Manual for the Child Behavior Checklist/4-18 and 1991 Profile. Burlington (Vermont), University of Vermont, Department of Psychiatry, 1991.

Achenbach TM, Rescorla LA: Manual for the ASEBA School-Age Forms and Profiles. Burlington (Vermont), Research Center for Children, Youth, and Families, 2001.

American Psychiatric Association. Diagnostic and Statistical Manual of Mental Disorders, $4^{\text {th }}$ ed., Text Revision (DSM-IV-TR). Washington (DC), Amerian Psychiatric Association, 2000.

Connors CK: Conners' Rating Scales-Revised: Technical Manual. North Tonawanda (New York), Multi-Health Systems Inc., 1997.

DeVillis RF: Scale development: theory and applications. Thousand Oaks (California), Sage Publications, 1991.

DuPaul GJ: Parent and Teacher Ratings of ADHD Symptoms: Psychometric Properties in a Community-Based Sample. J Clin Child Psychology 20:245-253, 1991.

Faries DE, Yalcin I, Harder D, Heiligenstein JH: Validation of the ADHD Rating Scale as a clinician administered and scored instrument. J Attention Disorders 5:107-115, 2001.

Gorin AA, Stone AA: Recall biases and cognitive errors in retrospective self-reports: A call for momentary assessments. In: Handbook of Health Psychology. Edited by Baum A, Revenson TA, Singer JE. Mahwah (New Jersey), 2001, pp 405-413.

Henker B, Whalen CK, Jamner LD, Delfino RJ: Anxiety, affect, and activity in teenagers: Monitoring daily life with electronic diaries. J Am Acad Child Adolesc Psychiatry, 41:660-670, 2002.

Kaufman J, Birmaher B, Brent D, Rao U, Flynn C, Moreci P, Williamson D, Ryan N: Schedule for Affective Disorders and Schizophrenia for SchoolAged Children-Present and Lifetime Version (KSADS-PL): Initial Reliability and Validity Data. Am Acad Child Adolesc Psychiatry, 36: 980-988, 1997. Knight D, Hensley VR, Waters B: Validation of the Children's Depression Scale and the Children's Depression Inventory in a prepubertal sample. J Child Psycho Psychiatry Allied Discip, 29: 853-863, 1988.

Kovacs M: Children's Depression Inventory (CDI) Manual. North Tonawanda (New York), MultiHealth Systems Inc., 1992.

Kratochvil CK, Perwien A, Vaughan B, Faries D, Saylor K, Busner J, Buermeyer C, Wong H, Swindle R: Emotional expression and ADHD pharmacotherapy in children: A new measure. AACAP Annual Meeting , 2004 (poster). 
March J S, Parker J D, Sullivan K, Stallings P, Conners CK: The Multidimensional Anxiety Scale for Children (MASC): Factor structure, reliability, and validity. J Amer Acad Child Adolesc Psychiatry 36:554-565, 1997.

Perwien AR, Kratochvil CJ, Faries DE, Vaughan B, Busner J, Saylor KE, Buermeyer CM, Kaplan S, Swindle R: Emotional expression in children treated with ADHD medication: Development of a new measure. (Submitted.)

Reich W, Welner Z, Herjanic B: Manual for the Diagnostic Interview for Children and Adolescents-IV (DICA-IV). North Tonawanda (New York), Multi-Health Systems Inc. Inc., 1997.

SAS Institute Inc. SAS/STAT User's Guide, Version 9, Cary, NC: SAS Institute, Inc., 1999.

Whalen CK, Henker B, Granger DA: Ratings of medication effects in hyperactive children:
Viable or vulnerable? Behav Assess 11:179-199, 1989.

Wyrwich KW, Tierney WM, Wolinsky FD: Further evidence supporting an SEM-based criterion for identifying meaningful intra-individual changes in health-related quality of life. J Clin Epidemiol 52:861-873, 1999.

Address reprint requests to: Dr. Chris Kratochvil University of Nebraska Medical Center Omaha, NE

E-mail: ckratoch@unmc.edu 


\section{APPENDIX}

\section{EESC Version 1}

Read each statement carefully and mark your response based on when your child is on his/her current ADHD medication. Think about the past two weeks. There are no right or wrong answers.

\begin{tabular}{llcccc} 
On ADHD medication ... & $\begin{array}{c}\text { Not at all } \\
\text { true }\end{array}$ & $\begin{array}{c}\text { A little } \\
\text { true }\end{array}$ & $\begin{array}{c}\text { Somewhat } \\
\text { true }\end{array}$ & $\begin{array}{c}\text { Pretty much } \\
\text { true }\end{array}$ & $\begin{array}{c}\text { Very much } \\
\text { true }\end{array}$ \\
\hline 1. My child does not talk enough & 1 & 2 & 3 & 4 & 5 \\
2. My child's mood is flat & 1 & 2 & 3 & 4 & 5 \\
3. My child has sparkle in his/her personality & 1 & 2 & 3 & 4 & 5 \\
4. My child seems happy & 1 & 2 & 3 & 4 & 5 \\
5. My child gets upset easily & 1 & 2 & 3 & 4 & 5 \\
6. My child seems easy going & 1 & 2 & 3 & 4 & 5 \\
7. My child's personality has blossomed & 1 & 2 & 3 & 4 & 5 \\
8. My child's personality seems "dampened" & 1 & 2 & 3 & 4 & 5 \\
9. My child is outgoing & 1 & 2 & 3 & 4 & 5 \\
10. My child seems down & 1 & 2 & 3 & 4 & 5 \\
11. My child just doesn't seem to be him/herself & 1 & 2 & 3 & 4 & 5 \\
12. My child stays to him/herself & 1 & 2 & 3 & 4 & 5 \\
13. My child is tearful & 1 & 2 & 3 & 4 & 5 \\
14. My child's true personality comes through & 1 & 2 & 3 & 4 & 5 \\
15. My child is sluggish & 1 & 2 & 3 & 4 & 5 \\
16. My child zones out & 1 & 2 & 3 & 4 & 5 \\
17. My child lacks his/her spark & 1 & 2 & 3 & 4 & 5 \\
18. My child is irritable or cranky & 1 & 2 & 3 & 4 & 5 \\
19. My child shows a range of emotions & 1 & 2 & 3 & 4 & 5 \\
20. My child is enthusiastic towards life & 1 & 2 & 3 & 4 & 5 \\
21. My child is friendly & 1 & 2 & 3 & 4 & 5 \\
22. My child's emotions seem flat & 1 & 2 & 3 & 4 & 5 \\
23. My child has mood swings & 1 & 2 & 3 & 4 & 5 \\
24. My child is spontaneous & 1 & 2 & 3 & 4 & 5 \\
25. My child is overly sensitive & 1 & 2 & 3 & 4 & 5 \\
26. My child is affectionate & 1 & 2 & 3 & 4 & 5 \\
27. My child is funny & 1 & 2 & 3 & 4 & 5 \\
28. My child is creative & 1 & 2 & 3 & 4 & 5 \\
29. My child is confident & 1 & 2 & 3 & 4 & 5 \\
\hline
\end{tabular}

Positive Subscale: items 3, 4, 6, 7, 9, 14, 20, 21, 24, 26, 27, 28, and 29.

Flat Subscale: items 1, 2, 8, 10, 11, 12, 15, 16, 17, and 22.

Emotional Lability Subscale: items 5, 13, 18, 23, and 25.

Note: The following revisions were proposed for Version 2.0 (Perwien et al., submitted):

The following items are deleted: items 19, 1, 2, 8, 10, 12, 15, 17, 22.

The following items are added: My child seems "blah" sometimes; My child isn't very social sometimes; My child doesn't have much spunk sometimes; My child could care less what happens at times; My child seems too slowed down sometimes; My child seems somewhat distant at times; My child looks somewhat zoned out at times; My child's emotions appear a little flat at times.

Copyright (C) 2006 Eli Lilly and Company and University of Nebraska

For permission to use the scale free of charge, please contact Dr. Chris Kratochvil, Psychopharmacology Research Center, University of Nebraska Medical Center: ckratoch@unmc.edu 


\section{This article has been cited by:}

1. Ralf W. Dittmann, Tobias Banaschewski, Alexander Schacht, Peter M. Wehmeier. 2014. Findings from the observational COMPLY study in children and adolescents with ADHD: core symptoms, ADHD-related difficulties, and patients' emotional expression during psychostimulant or nonstimulant ADHD treatment. ADHD Attention Deficit and Hyperactivity Disorders . [CrossRef]

2. Lisa Weyandt, George J. DuPaul, Genevieve Verdi, Joseph S. Rossi, Anthony J. Swentosky, Brigid S. Vilardo, Sean M. O’Dell, Kristen S. Carson. 2013. The Performance of College Students with and without ADHD: Neuropsychological, Academic, and Psychosocial Functioning. Journal of Psychopathology and Behavioral Assessment 35:4, 421-435. [CrossRef]

3. Alain Katic, Bryan Dirks, Thomas Babcock, Brian Scheckner, Ben Adeyi, Cynthia Richards, Robert L. Findling. 2013. Treatment Outcomes with Lisdexamfetamine Dimesylate in Children Who Have Attention-Deficit/Hyperactivity Disorder with Emotional Control Impairments. Journal of Child and Adolescent Psychopharmacology 23:6, 386-393. [Abstract] [Full Text HTML] [Full Text PDF] [Full Text PDF with Links]

4. Rakesh Jain, Thomas Babcock, Teodor Burtea, Bryan Dirks, Ben Adeyi, Brian Scheckner, Robert Lasser, John Renna, Don Duncan. 2013. Efficacy and Safety of Lisdexamfetamine Dimesylate in Children with Attention-Deficit/Hyperactivity Disorder and Recent Methylphenidate Use. Advances in Therapy 30:5, 472-486. [CrossRef]

5. Jonathan Posner, Tiago V. Maia, Damien Fair, Bradley S. Peterson, Edmund J. Sonuga-Barke, Bonnie J. Nagel. 2011. The attenuation of dysfunctional emotional processing with stimulant medication: An fMRI study of adolescents with ADHD. Psychiatry Research: Neuroimaging . [CrossRef]

6. Atilla Turgay, Lawrence Ginsberg, Elias Sarkis, Rakesh Jain, Ben Adeyi, Joseph Gao, Bryan Dirks, Thomas Babcock, Brian Scheckner, Cynthia Richards, Robert Lasser, Robert L. Findling. 2010. Executive Function Deficits in Children with AttentionDeficit/Hyperactivity Disorder and Improvement with Lisdexamfetamine Dimesylate in an Open-Label Study. Journal of Child and Adolescent Psychopharmacology 20:6, 503-511. [Abstract] [Full Text HTML] [Full Text PDF] [Full Text PDF with Links]

7. Robert L. Findling, Lawrence D. Ginsberg, Rakesh Jain, Joseph Gao. 2009. Effectiveness, Safety, and Tolerability of Lisdexamfetamine Dimesylate in Children With Attention-Deficit/Hyperactivity Disorder: An Open-Label, Dose-Optimization Study. Journal of Child and Adolescent Psychopharmacology 19:6, 649-662. [Abstract] [Full Text HTML] [Full Text PDF] [Full Text PDF with Links]

8. Caroline Skirrow, Gráinne McLoughlin, Jonna Kuntsi, Philip Asherson. 2009. Behavioral, neurocognitive and treatment overlap between attention-deficit/hyperactivity disorder and mood instability. Expert Review of Neurotherapeutics 9:4, 489-503. [CrossRef]

9. 2007. Prescriptions Into Practice. Child and Adolescent Psychopharmacology News 12:5, 4-10. [CrossRef] 